\title{
The Impact of Early Earth Differentiation on the Modern World
}

\author{
RICHARD W. CARLSON1
}

1Carnegie Institution for Science, Earth \& Planets Laboratory, Washington, DC, 20015 USA:

rcarlson@carnegiescience.edu

Earth is unique amongst the terrestrial planets in its continuing geologic activity and its production of a silica-rich continental crust via plate subduction. The rate of crust formation and recycling through time remains a topic of considerable debate because the amount of crust that has been recycled and mixed into the mantle is difficult to constrain. The short-lived $146 \mathrm{Sm}-142 \mathrm{Nd}$ system provides clear evidence for differentiation events on Earth that occurred within 100-150 Ma of Solar System formation. Based on their $142 \mathrm{Nd} / 144 \mathrm{Nd}$ ratios, Eoarchean rocks in different terranes were formed from either LREE enriched or depleted sources that have model ages in the range of 4.4-4.5 Ga. Eoarchean terranes derived from LREE-enriched sources follow $\mathrm{Hf}$ isotope evolution lines consistent with the reworking of Hadean mafic crust (Carlson et al., Chem. Geol., 2019). The observed degree of variability in $142 \mathrm{Nd} / 144 \mathrm{Nd}$ in early Archean rocks is much diminished in late-Archean rocks and barely, if at all, resolved in modern mantle-derived rocks. These results suggest that the major fraction of primary mafic crust produced in Earth's initial differentiation was effectively recycled and mixed into Earth's interior by the end of the Archean. The preservation in late-Archean and post-Archean mantle-derived rocks of superchondritic initial isotopic compositions in the long-lived $147 \mathrm{Sm}-143 \mathrm{Nd}$ and Lu-Hf systems suggests that the composition of the portion of the mantle involved in crust formation is slightly incompatible element depleted in comparison to estimates of the bulk silicate Earth based on chondritic meteorites. A reservoir formed at $4.4 \mathrm{Ga}$ with a $147 \mathrm{Sm} / 144 \mathrm{Nd}=0.21$ will evolve to a present day e143Nd $=$ +8 , the average value of MORB (Gale et al., G3, 2013). This reservoir will have a present day $142 \mathrm{Nd} / 144 \mathrm{Nd}$ about $7 \mathrm{ppm}$ higher than a similar age source that has chondritic $\mathrm{Sm} / \mathrm{Nd}$. This offset in $142 \mathrm{Nd} / 144 \mathrm{Nd}$ is similar to that seen between the modern accessible Earth and enstatite chondrites (Boyet et al., EPSL, 2018) and the Moon (Sprung et al., EPSL, 2013; Carlson et al., Phil. Trans., 2014). The depleted MORB mantle thus could be a remnant of early Earth differentiation that occupies a major fraction of the mantle in which case its degree of incompatible element depletion has been only marginally increased by extraction of the continental crust. 